\title{
Chemical Adulterants in Herbal Medicinal Products: A Review
}

Authors

Affiliations
Jacob Calahan ${ }^{1}$, Dylan Howard ${ }^{1}$, Ahmad J. Almalki ${ }^{1,2}$, Mahabir P. Gupta ${ }^{3}$, Angela I. Calderón ${ }^{1}$

${ }^{1}$ Department of Drug Discovery and Development, Harrison School of Pharmacy, Auburn University, Auburn, AL, USA

2 Department of Pharmaceutical Chemistry, Faculty of Pharmacy, King Abdulaziz University, Jeddah, Kingdom Saudi Arabia

${ }^{3}$ Centro de Investigaciones Farmacognósticas de la Flora Panameña, Facultad de Farmacia, Universidad de Panamá, Panamá, República de Panamá
Key words

- chemical adulterants

toxicity

- analytical techniques

- detection
- herbal medicinal products

\begin{abstract}
$\nabla$

Many herbal medicinal products have been found to contain synthetic prescription drugs as chemical adulterants. This has become evident by the number of toxicity cases and adverse reactions reported in which casualties were reported via analytical techniques that detected the presence of chemical adulterants in them, which could be responsible for their toxicity. The adulteration of herbal medicinal products with synthetic drugs continues to be a serious problem for regulatory agencies. This review provides up to date information on cases of toxicity, major chemical adulterants in herbal medicinal products, and current analytical techniques used for their detection.
\end{abstract}

\section{Abbreviations \\ $\nabla$ \\ AAPCC: American Association of Poison Control Centers \\ AER: $\quad$ adverse event reporting \\ API: active pharmaceutical ingredient}

\section{Introduction}

$\nabla$

10.1055/s-0042-103495

Published online April 7, 2016

Planta Med 2016; 82: 505-515

(c) Georg Thieme Verlag KG

Stuttgart $\cdot$ New York .

ISSN 0032-0943

\section{Correspondence}

\section{Dr. Angela I. Calderón}

Department of Drug Discovery and Development

Harrison School of Pharmacy

Auburn University

4306 Walker Building

Auburn, AL 36849

USA

Phone: + 13348448333

Fax: + 13348448331

aic0001@auburn.edu
During the recent years, there has been a resurgence in the use of HMPs, which may be due to growing consumer dissatisfaction with conventional medicines and an increase in automedication. HMPs are those medicinal products that exclusively contain herbal drugs as ingredients (e.g., parts of plants) or pharmaceutical preparations thereof (e.g., extracts, essential oils, etc.). In the United States, a botanical product, depending upon its labeling and intended use, may be a food, a dietary supplement, a drug, a medical device (gutta-percha), or a cosmetic. With herbal supplements becoming a more popular complement to living a healthy life, the adulteration of HMPs
ATR-IR: attenuated total reflectance-infrared spectroscopy

BMPEA: $\quad \beta$-methylphenylethylamine

CE: $\quad$ capillary electrophoresis

CE-MS: capillary electrophoresis-mass spectrometry

DFT: density functional theory

EP: ephedrine

FDA: $\quad$ Food and Drug Administration

GFSE: grapefruit seed extract

HMP: herbal medicinal product

MEP: methylephedrine

MRM: multiple reaction monitoring

NEP: $\quad$ norephedrine

NSAIDs: nonsteroidal anti-inflammatory drugs

PDA: photodiode array

PDE-5i: phosphodiesterase-5 inhibitor

PP-THHS: propoxyphenyl-thiohydroxyhomosildenafil

PSE: pseudoephedrine

ROS: $\quad$ rosiglitazone maleate

TLC-SERS: thin-layer chromatography surfaceenhanced Raman spectrometry

TOF: time-of-flight

with synthetic potent drugs is a major concern for drug regulatory agencies as they pose serious health risks. There have been many reports of adulterated herbal supplements that were claimed to be "all natural." For example, many herbal supplements claiming to improve sexual performance and vitality were found to contain sildenafil (Viagra) [1]. In order to detect the adulterants in HMPs, Liang et al. [2] made an attempt to screen multiple herbal supplements for adulterants in one LC-MS run.

The current review provides a comprehensive literature on cases of toxicity due to chemical adulterants in botanical dietary supplements from 1990 to 2015, and a review of various analytical methods used for their detection. The search 
Table 1 Common chemical adulterants in HMPs since 2004 [3-9].

\begin{tabular}{llll} 
Adulterant & \# Samples Examined & \# Positive Results & Claim \\
\hline Sildenafil & 81 & 28 & Enhancing sexual performance \\
\hline Famotidine & 47 & 18 & Digestive disorders \\
\hline Ibuprofen & 14 & 3 & Arthritis \\
\hline Promethazine & 19 & 2 & Tranquilizer effect or improving “health status" of old people \\
\hline Diazepam & 11 & 3 & Dysphoria and insomnia \\
\hline Nifedipine & 16 & 6 & Hypertension, angina pectoris, and cardiovascular health \\
\hline Captopril & 19 & 8 & Hypertension \\
\hline Amoxicillin & 22 & 2 & Tracheitis \\
\hline Dextromethorphan & 22 & 4 & Alleviation of cough and expectorant effect
\end{tabular}

terms used were adulteration of HMPs, herbal medicine, traditional medicine, traditional Chinese medicine, dietary supplement, adulterant, synthetic drugs, contaminant, and illegally added and undeclared drug. All of the reports found were observed and analyzed via SciFinder, PubMed, Google Scholar, and FDA databases. Reports on contaminants by heavy metals and pesticides were excluded. Reports on intentional adulteration of herbal medicines and dietary supplements with synthetic drugs were collected and are shown in $\bullet$ Table 1.

In addition to the most common chemical adulterants listed in - Table 1, the following adulterants: antidiabetic drugs (glibenclamide, rosiglitazone, and metformin), antihypertensive drugs (amlodipine, indapamide, valsartan, clonidine, and hydrochlorothiazide), synthetic glucocorticoids, NSAIDs, phenylbutazone, aminopyrine, indomethacin, hydrocortisone, dexamethasone, ibuprofen, diclofenac, salicylic acid, naproxen, and acetaminophen are all considered to be additives used for intentional adulteration of acclaimed herbal medicinal products.

Based on the notion that adulteration of botanical ingredients can be accidental or deliberate, the American Botanical Council is making efforts to counteract these practices. The ABC-AHPNCNPR Botanical Adulterants Program focuses on both accidental adulteration as well as intentional adulteration of plant-based products for financial gain. This industry-funded program aspires to serve as a self-regulatory mechanism for industry to address adulteration problems through education rather than federal regulation. The ABC-AHP-NCNPR Botanical Adulterants Program, which is now cosigned by Canada, is a long-term, multiparty coalition of herb quality and identity experts in university research groups, third-party analytical laboratories, government agencies, trade associations, and industry companies to examine the extent of suspected adulteration of herbal materials, particularly adulteration that is economically motivated. The intention is to confirm the extent of adulteration in the United States and global markets, determine which official or unofficial analytical methods are currently available to help detect the presence (or absence) of a suspected or known adulterant, and to provide comment and guidance on the relative strengths and/or weaknesses of differing analytical methods [10].

Although HMPs are used worldwide, regulations on quality assurance vary from country to country. There are four major national frameworks of regulating HMPs: United States of America, European Union (EU), Canada, and Australia. In the United States, "botanical products" are regulated as dietary supplements and do not require FDA approval unless they include a new dietary ingredient, in which case a premarket notification must be submitted to the FDA. There are also two HMPs registered as drugs in the United States under the Federal Food, Drug, and Cosmetic Act. These are Veregen ${ }^{\circledR}$ (topical catechins from green tea) for genital warts and Fulyzaq ${ }^{\circledR}$ (oral Crofelmer) obtained from Sangre de Drago (latex of Croton lechleri Müll. Arg., Euphorbiaceae) for the treatment of diarrhea in AIDS patients.

In Canada, they are regulated under the Natural Health Products Regulations, which are distinct from the Food and Drugs Regulations. On the other hand, HMPs and other complementary medicines are regulated as medicines under the Therapeutic Goods Act in Australia using a risk-based approach with a two-tiered system: lower risk medicines can be listed on the Australian Register of Therapeutic Goods (ARTG), while higher risk medicines must be registered on the ARTG.

The European Union Legislation on pharmaceutical products for human use also applies, in general, to traditional herbal medicines. However, in order to overcome difficulties encountered by member states in applying pharmaceutical legislation to traditional herbal medicinal products in a uniform manner, a simplified procedure was introduced in 2004. The simplified procedure was introduced by Directive 2004/24/EC/pdf of the European Parliament and of the Council of 31 March amending as a traditional herbal medicinal product Directive 2001/83/EC on the community code relating to the medicinal products for human use. The simplified procedure allows the registration of herbal medicinal products without requiring trials of safety and efficacy, provided that there is sufficient evidence of traditional medicinal use of the product throughout a period of at least 30 years, including the 15 years in the Community. With regard to the manufacturing of these products and their quality, application for registration of traditional herbal medicinal products have to fulfill the same requirements as applications for marketing authorization [11].

All of the frameworks mentioned incorporate methods of reporting adverse events (AERs). Most people do not report adverse reactions because they consider HMPs harmless, being "natural products." Valuable HMPs AER information is available from sources such as Natural Medicine Watch, FDA MedWatch, Canada Vigilance Program, WHO-Uppsala Monitoring Centre, Australian Therapeutic Goods Administration, and the British Medicines and Healthcare Products Regulatory Agency (MHRA).

According to data in 2006 from the AAPCC [12], there were 972073 exposures to pharmaceutical products resulting in adverse reactions. Of the adverse reactions reported, 73364 of them were due to dietary supplements and vitamins, with 42 major outcomes and 3 deaths.

The Dietary Supplements Information Expert Committee (DSI-EC) of the Pharmacopoeial Convention (USP) conducted a review in 2008 [13] that looked over the safety guidelines and reporting systems currently in place for dietary supplements. It was found that there is a difficulty in reporting AERs because dietary supplements contain multiple ingredients, which leaves 
room for contamination, substitution of herbs or botanicals, and adulteration. Along with those risks when AERs were reported, it is difficult to interpret the data because of a lack of case information, unknown manufacturers, and unknown variable patient history. The primary reporting portal for the FDA, MedWatch, again was found to receive fewer reports than Poison Control Centers and with the limited coordination between the two, this leaves the public with potential health risks. The DSI-EC concluded that there needs to be enhanced data collection approaches, improved coordination of AER surveillance programs, strengthened educational programs for both public and health care sectors, and research conducted concerning the safety of dietary supplements in order to help resolve the issue of dietary supplement AERs.

The FDA has attempted to increase AERs by taking advisory actions and lawsuits against dietary supplement manufacturers. However, their efforts seem to be insufficient. Of AERs during 2008 and 2010, there were over 1000 more cases reported to the AAPCC than the FDA [14]. This poses the question of whether coordination between the two to address this issue would be enough to bring this dilemma to the public eye and cause a change in manufacturing regulation.

In 2012, an active surveillance of dietary supplement AERs was conducted for 112 weeks, in which the pharmacies participating would ask patients getting prescriptions about their combined use of dietary supplements and prescription medications over the past 3 months and if they had any AERs [15]. Of the 2615 patients screened, 1037 of them reported use of dietary supplements in combination with prescription medications. Only 15 patients of the 77 with possible AERs were available for later interview and 4 of those 15 were determined to "probably" be due to dietary supplement use. In the first case, a 19-year-old male patient with a history of depression, neuropathic pain, and delayed sleep phase disorder added melatonin to his recurrent prescriptions of citalopram, nortriptyline, and oxycodone presented what he described as severe sedation. Another patient, a 53-year-old female with asthma and symptoms of menopause and depression/anxiety, was hospitalized with jaundice and fatigue. She was diagnosed with hepatic necrosis and had been taking 13 different products, several of which were dietary supplements for weight loss along with several of her prescription medicines. The study concluded that passive surveillance was not very effective time and time again and is not a very reliable approach, and that the potential advantages of active surveillance could be the best route in finding and minimizing dietary supplement AERs. From the perspective of regulations and compliance enforcement, it is important to note that an HMP such as a dietary supplement in the United States that is adulterated with a drug is legally no longer an HMP or dietary supplement but is an unauthorized drug. This is an important distinction with regard to penalties that regulators can impose to help protect consumers from the potentially dangerous products. More information on the regulations of herbal medicinal products can be found in a review by Gupta [16].

The current review provides a comprehensive literature on cases of toxicity due to chemical adulterants in botanical dietary supplements from 1990 to 2015 and various analytical methods used for their detection.

\section{Case Reports of Toxicity Due to Chemical Adulterants}

\section{$\nabla$}

Perhaps the greatest risk to people from HMPs is adulteration with common drugs for cases like sleep aids (clonazepam), weight loss (sibutramine and fenfluramine), diabetes (glibenclamide), and bodybuilding (steroids) products. Specifically, the product PC-SPES (a mixture of eight herbs manufactured by Botanic Lab Inc.) was used for prostate cancer. It caused a change in several genes associated with microtubule dynamics by adulteration with ethinylestradiol, warfarin, and indomethacin [8].

Dietary foods and herbal weight loss supplements have become very popular with the recent fad of staying in shape and looking healthy. Fenfluramine has now been banned by the FDA in the U.S. and in Hong Kong after reporting problems with pulmonary hypertension and valvular disease [17]. An analogue of fenfluramine, $\mathrm{N}$-nitrosofenfluramine, is reported to be responsible for more than 800 hepatotoxicity cases in Japan as well as in Singapore and the United Kingdom [18-20]. The majority of patients recovered and those who did not either died or developed fulminant hepatic failure. Sibutramine was formerly approved by the FDA and is generally well tolerated. Its common side effects are headache, constipation, nausea, dizziness, dry mouth, and insomnia [21]. It is associated with high blood pressure and increased heart rate. Recently, it has been related to manic episodes, panic attacks, and mood swings [22-24]. The problems with sibutramine were also reported in Japan and Taiwan [25, 26]. Sibutramine, as mentioned previously, is a drug that has been intentionally added to slimming products as an appetite suppressant [27]. This was extremely popular in HMPs until it was banned in both Europe and the United States in 2010 for its potential cardiovascular risks or even strokes $[28,29]$. Sibutramine also has the potential to interact with other medications and cause serotonin syndrome [29]. Patients from Hong Kong reported side effects after taking one of the three over-the-counter slimming products to the Hospital Authority Toxicology Reference Laboratory between 2004 and 2006. During this period, 979 patients were referred to the laboratory; however, only 42 had possible ailments related to the weight-loss products. Twenty-eight of the patients tested positive in their urine samples for fenfluramine, non-prescribed sibutramine, non-prescribed thyroid hormones, and undeclared Western weight-loss drugs. Adulterants included sibutramine and its analogue, fenfluramine and its analogue, phenolphthalein, thyroid tissues, propranolol, hydrochlorothiazide, mazindol, and caffeine [26].

Another adulteration case with Tung Shueh pills in Taiwan was of acute renal failure; although, it was not established as to which adulterant caused this adverse reaction. In Singapore, Tung Shueh pills used for pain relief were adulterated with caffeine, diazepam, indomethacin, and prednisolone, which can cause mental depression, bone loss, spontaneous fractures, intestinal bleeding, and even coma [3]. Additionally, an herbal supplement, Gu Ben Wan, used to treat dry cough was found to contain six undeclared adulterants [3].

With the increased popularity of using herbal supplements in the last few years, countries are becoming increasingly aware of the need to screen these drugs. For example, in the FDA Tainted Supplements Report from 2007 to 2012, 332 dietary supplement products were adulterated. Of these, more than $95 \%$ were sexual performance enhancement products [29]. Many herbal supplements claiming to have sexual enhancement properties are adulterated with PDE-5is like sildenafil, tadalafil, and vardenafil. There are more than 50 analogues of these products with minor 
structural modifications that may have the same desired pharmacological properties $[30,31]$. Since many of these analogues are difficult to detect and never went through the thorough preclinical and clinical studies needed for market authorization, their toxicity is unknown, thus becoming a serious safety concern to the public [31]. Gilard et al. [32] believe that the combination of ${ }^{1} \mathrm{H}$ NMR and mass spectroscopy is the easiest method to detect these analogues. In their study, they analyzed 150 sexual enhancement herbal supplements that claimed to be "pure" and found that $61 \%$ of them were adulterated with at least one PDE5i. Additionally, eight herbal supplements contained sexual dysfunction drugs (flibanserin, yohimbine, phentolamine) or hormones (DHEA, testosterone). It was found that 59 of the 92 adulterated products contained only one drug, while the other 33 contained two or more adulterants. The most frequent adulterants found were sildenafil analogues, which accounted for $51 \%$ of the adulterants used, followed by tadalafil.

A screening carried out by the Health Science Authority in Singapore from 1990 to 2001 found adulterants in 41 of 3320 Chinese medicinal products, of which 19 contained synthetic drugs. Of these, 12 of them claimed to treat sexual dysfunction in males by intentionally using adulterants such as sildenafil, tadalafil, and vardenafil $[3,33]$. These findings provide the necessary evidence of why herbal supplements should be screened in order to keep the customers safe from unintended side effects.

Cohen et al. [34] at the Harvard University Medical School conducted a recent study on weight-loss and sports enhancement herbal products containing Acacia rigidula Benth. (Fabaceae), in which 11 of the 21 products tested contained BMPEA, a synthetic isomer of amphetamine. BMPEA has been used in dietary supplements since 2010, but its safety and efficacy in humans have not been studied. Research on the association of $A$. rigidula and BMPEA was first done in the 1960s and then again in the 1990s. The initial research concluded that $A$. rigidula contained large amounts of methamphetamine and mescaline (both Schedule 1 controlled substances). More recent research shows that there were significant errors in the initial research, likely due to aggressive extraction and older analytical techniques, and that either these products were not found in A. rigidula or they were in such low quantities they would have almost no effect. The Harvard research team released a case report on a 53-year-old woman who suffered a hemorrhagic stroke, which they concluded was likely due to a combination of a BMPEA-containing supplement the woman had been taking and exercise [35]. The publication of this study followed a major investigation conducted by the New York Attorney General on failed DNA barcode tests for identity in herbal dietary supplement products. Possibly, at least partially, in response to external pressure from the New York Attorney General and calls from three United States Senators, the FDA sent letters to five companies warning them about BMPEA in their products and also banned the sale of BMPEA. The lead author of the Harvard Study, Pieter Cohen, said that the FDA's action was a step toward the right path but it was a small one. Cohen proclaimed that the letters only dealt with companies who openly labeled BMPEA on their products, rather than addressing companies that solely label $A$. rigidula on their products and conceal the spiking with BMPEA [35].

A study of 489 cases from the U.S. Poison Control Centers was conducted in the United States over one year associated with adverse reactions to dietary supplements [36]. The cases were selected using a multitier review process leading to at least a $50 \%$ certainty that the negative events were associated with dietary supplements; however, 93\% of the side effects were considered mild in all age groups and on organ systems. A more recent oneyear study from the California Poison Control System reported two-thirds of the adverse reactions were associated with dietary supplements and a majority of them were classified as moderate to serious. The most common contaminants were caffeine, yohimbine, bitter orange, and gentian. Some adverse reactions involved blood coagulation disorders attributable to fish oil, ginkgo, and vitamin E [36].

The China Food and Drug Administration (CFDA) released documentation in 2015 explaining recent ginkgo production containing adulterants. It was discovered that the pharmaceutical companies substituted 3\% hydrochloric acid for ethanol and water [37]. Another case claims the manufacturers used purchased ginkgo extract from eight other companies to produce ginkgo supplements. These pharmaceutical companies along with some others were forced to discontinue their products after these discoveries of false advertisement were made public.

In one study, Mathon et al. [38] found HPTLC coupled with UV densitometry a suitable technique for both the identification and quantification of sibutramine in dietary supplement products. This study was conducted over a two-year period in which around 50 dietary supplements were purchased on the Internet. They bought 39 products in 2010 when sibutramine was initially banned from markets and 13 in 2012 to see if the manufacturers were complying with this ban. The product label did not mention sibutramine and the products were advertised as natural weightloss products. Of the 39 products bought in 2010, 17 (44\%) of them were found to contain the adulterant sibutramine in quantities ranging from 3 to $35 \mathrm{mg}$ per capsule. This shows that someone could have taken three times the recommended dosage in one capsule before it was banned in Europe [39]. From the 13 products purchased in 2012, 9 (69\%) of them contained sibutramine. The quantities ranged from trace amounts to $10 \mathrm{mg}$ per capsule. Even though the concentration of sibutramine in natural weight-loss products has decreased, the percentage of products in which it is found has increased, which poses a threat to customers. This also shows that the manufacturers were not complying with the FDA ban.

Drugs that have herbal formulations for body strength, memory, sexual potency, weight loss, and diabetes with very high sales have been known to be intentionally adulterated by the manufacturers. For example:

- Poon et al. [40] analyzed "Chang Qing Chun” weight-loss capsules and found the presence of significant quantities of undeclared caffeine, anthraquinones, riboflavin, nicotinamide, pyridoxine, N-nitrosofenfluramine, fenfluramine, sibutramine, phenolphthalein, and propranolol. Another herbal formulation called "Qing Zhi Mei" was also found to contain caffeine, anthraquinones, ephedrine, fenfluramine, propranolol, and phenolphthalein as well as animal thyroid tissue.

- A product named Qnexa claimed to help people lose weight and lower blood pressure, blood sugar, and cholesterol. However, the FDA banned it in 2010 because of its dangerous side effects [41].

Spice, an herbal mixture found in several European nations, became available in 2004 as a legal alternative to cannabis, which substantially increased its popularity [42]. Spice Silver, Spice Gold, Spice Diamond, Yucatan Fire, and Smoke are common names of Spice's early use as incense. There were several herbs labeled as ingredients, but no synthetic additives; additionally, they claimed to have the same effects as cannabis without an 
Table 2 Comparison of analytical techniques.

\begin{tabular}{|c|c|c|}
\hline Technique & Advantages & Disadvantages \\
\hline LC-MS \& HPLC [49] & Analyzes most compounds & $\begin{array}{l}\text { ESI is difficult to contribute to spectral databases based on } \\
\text { available standards in different labs }\end{array}$ \\
\hline GC\& GC-MS [50] & High resolution and sensitivity, good accuracy, rapid & Only separates volatile compounds \\
\hline${ }^{1} \mathrm{H}$ NMR [51] & Detects specific structural components & Expensive, time-consuming \\
\hline CE \& CE-MS [52] & $\begin{array}{l}\text { Small amounts of sample and solvent have high separation } \\
\text { efficiency, short analysis time, inexpensive }\end{array}$ & Improvements can be made with accuracy \\
\hline TLC \& HPTLC [53] & Simple, rapid, inexpensive, can use several different solvents & $\begin{array}{l}\text { Short stationary phase, high detection limit, can be affected } \\
\text { by humidity and temperature }\end{array}$ \\
\hline
\end{tabular}

age restriction [42]. The following synthetic additives were found in 2008: the C8 homologues of the non-classical cannabinoid CP-47, 497 and the aminoalkylindole JWH-018 [43,44]. Both of the adulterants are potent cannabimimetics. In spite of this, its popularity spread into the USA, Germany, and Russia and still contained at least one synthetic additive of a cannabinoid. Cardiovascular and psychological (i.e., panic attacks) disorders are common symptoms reported with the use of Spice, which are the same symptoms reported with high dosages of cannabis. Some cases have been reported in German and Italian hospitals of high toxicity after consuming brands containing JWH-122 [45]. Patients who were hospitalized had muscular spasms and/ or loss of consciousness, which required them to be placed on artificial ventilation. The use of this HMP is reportedly addictive compared to cannabis due to its rapid development of tolerance [45]. Spice is currently monitored in numerous countries and is regulated under national and federal laws in most.

Some more recent studies have persuaded the FDA to ban or restrict the sale of several HMPs that contain synthetic adulterants. The FDA identified these additives after examining them extensively during international shipments. All of the following cases are found from the FDA's database and were documented in May of 2015 [46].

- Ginseng She Lian Wan, which claimed to help alleviate joint pain, arthritis, and gout, is now banned by the FDA as its labs confirmed that it contains dexamethasone, a corticosteroid, and chlorpheniramine. The FDA is not aware of adverse reactions to this product; however, it is known to have complications with withdrawals from corticosteroids. Dexamethasone is also known to impair immunity, increase blood sugar, and cause muscle and psychiatric complications.

- Jianbu Huqian Wan also claimed to help consumers with their joint pain and was found to contain dexamethasone, chlorpheniramine, and furosemide. Chlorpheniramine is an antihistamine that can cause drowsiness. Furosemide is a potent diuretic that can cause dehydration and electrolyte imbalance that may lead to seizures, kidney damage, gastrointestinal problems, and coma.

- Saurean Fong Sep Lin is promoted for back pain and injury. It is unequivocally adulterated with dexamethasone and cyproheptadine. Cyproheptadine is an antihistamine that can cause drowsiness.

- Asihuri Plus Forte is used for joint and nerve pain. It was found to contain dexamethasone and phenylbutazone. Phenylbutazone is an NSAID that is discontinued in the United States due to its potential of severe bone marrow toxicity. This side effect is reversible in some cases, but in others it can be lethal.

- GFSE has been marketed as a natural product for over 30 years. The claimed ingredient is an extract of grapefruit seeds, but has been advertised today as a natural, antimicrobial agent for ec- zema, acne, cold sores, athlete's foot, thrush, colds, gastrointestinal disorders, sore throat, vaginal infections, gingivitis, and allergies. Some studies have shown that GFSE products contain microbicides such as benzalkonium chloride, benzethonium chloride, triclosan, and methyl p-hydroxybenzoate. The FDA has distributed Warning Letters to drug companies about the effects of GFSE products sold as dietary supplements [47].

In a study conducted by Geller at al. [48] at the Centers for Disease Control and Prevention, there were more than 23000 emergency room visits and 2154 hospitalizations annually from adverse reactions caused by the adulteration of dietary supplements. The supplements observed to cause these hospitalizations were primarily from multivitamins and supplements for iron, sleep, weight loss, and anxiety. The most common symptoms were chest pain and tachycardia associated with weight loss and bodybuilding supplements. Choking and difficulty swallowing were associated with multivitamins, but the majority of these cases were seen in elderly people.

\section{Analytical Techniques for Detection of Chemical Adulterants \\ $\nabla$}

Vaclavik et al. [49] published a review discussing the major MS methods based on publications from 1997 to 2014. The methods included were liquid chromatography, gas chromatography, flow injection, capillary electrophoresis, and ambient mass spectrometry for the screening of adulterants. The review then describes in detail the combinations of methods used and the findings from the authors. Vaclavik et al. [49] cover most of the screening techniques, however, they do not mention the newer techniques of TLC-SERS and ATR-IR. These methods were verified with some type of MS, but they omit MS from the technique and are intended for on-site screenings. The techniques covered in the current review were searched in publications in SciFinder from 2003 to 2015 ( Table 2).

\section{Mass spectrometry-based techniques}

LC-MS has become a key method in identifying compounds in HMPs and other botanical products, as it is capable of providing data on both the quantities and structures. This method was used for the detection of an extremely polar hypoglycemic drug, metformin, found in HMPs [54]. This concluded with a more separated and pure sample of metformin from matrix interferences. Another method utilized UHPLC, which distinguished 57 pharmaceuticals [55]. UHPLC has also been used to separate steroids, hypoglycemic products, and antihypertensive agents in dietary supplements, 17 non-opioid analgesics, and NSAIDs [56-58]. Ionization analysis of dietary supplements can be reviewed in a positive or negative mode. Negative ESI has been run to determine 
the presence of thiazide-type and other diuretics, estrogens, NSAIDs, salicylic acid, and valproic acid $[56,59,60]$. To obtain more data, the MRM fragment data of the compounds has been tested on anabolic steroids in various supplements [61]. To detect further selectivity, LC-QTOF-MS screenings of Indian aphrodisiac HMPs have found sildenafil, tadalafil, and vardenafil. A strategy for utilizing a more intense bioaffinity mass spectrometry has been used for the identification of anabolic steroids in HMPs $[62,63]$.

The applicability of GC-MS is determined by the volatility and thermal stability of analytes. A faster technique for GC-MS was discovered for the detection of sildenafil, tadalafil, and vardenafil in food and herbal products. A GC-MS method was successfully used for the screening of 134 pharmaceuticals in patent medications in China [64].

Flow injection-mass spectrometry (FI-MS) is a technique that allows for the sample being placed in a carrier to move directly into the atmospheric pressure interface of the mass spectrometer. This method has been tested on multiple PDE-5is in dietary supplements including sildenafil, tadalafil, and vardenafil [65]. Another study was carried out for weight-loss drugs including sibutramine and its analogues [66]. Tests were positive on comparing the ratios of referenced standards with the MRM calculations of the adulterants.

Ambient mass spectrometry is beneficial because it provides information very quickly using minimal sample preparation. A study using ambient mass spectrometry and direct analysis in real time (DART) has been conducted for the analysis of 7 hypoglycemic drugs in HMPs used to treat type 2 diabetes mellitus [67]. Another study utilized desorption corona beam ionization mass spectrometry (DCBI-MS) for analysis on 16 weight-loss regimens that included fenfluramine, phenolphthalein, and sibutramine and its analogues [68].

While using this method, two of the most common adulterants, sildenafil (Viagra) and famotidine, found in Chinese herbal supplements were looked at in further detail. Sildenafil is found in herbal supplements that claim to improve sexual performance. Eighty samples under suspicion of being adulterated with this drug were tested using this method and it was found that 28 contained sildenafil. The State Drug Administration of China used the HPLC method for testing the same drugs and found 34 adulterated supplements, but the method proposed by Liang et al. [2] proved that 6 of them were false positives. The second study aimed at finding the adulterant famotidine, which is found in supplements that claim to be useful in gastrointestinal distress and gastrosis. Liang et al. [2] tested 40 samples and found 18 of them to be positive for famotidine.

\section{Capillary electrophoresis}

CE-MS consists of electrokinetic separation of analyte groupings according to the ion mobility in an electric field. Capillary zone electrophoresis and micellar electrokinetic chromatography (MEKC) along with an ESI source was used to analyze 16 HMPs individually for the following analytes: NSAIDs, analgesics, antipyretic stimulants, and anxiolytics [69]. A more recent method of CE-MS was introduced for more adequate testing of adulterants in weight-loss dietary supplements.

Millions of people are affected by obesity worldwide. To help fight this, there are thousands of weight-loss supplements and diets that are advertised, some of which are herbal medicinal products. According to Brazilian legislation, all HMPs should contain exclusively raw vegetables and no synthetic drugs [70]. Bra- zilian studies have found HMPs adulterated with anorexic drugs (amfepramone and fenproporex), antidepressants (fluoxetine), and anxiolytics (benzodiazepines) [71,72]. Some side effects reported caused by these adulterants includes chest pain, nausea, insomnia, fatigue, palpitations, and headache [73]. Sibutramine has also been banned in Brazil, due to its presence in "natural" weight-loss products [74].

CE normally employs UV detection for analysis and is sometimes coupled with MS. CE has gained a reputation for its success in the separation of adulterants. Contactless conductivity $\left(C^{4} D\right)$ is capable of selectively screening amfepramone, fenproporex, sibutramine, fluoxetine, bupropion, sertraline, paroxetine, and flurazepam in HMPs; it can also separate cationic species. This hypothesis was tested in 106 samples in approximately half of Brazil's pharmacies [75].

$\mathrm{CE}$ is a beneficial and simple method because it is rapid, inexpensive, and requires fewer quantities of the samples. Caffeine (stimulant), furosemide (diuretic), and NEP and EP (stimulant, decongestant, and anorexics) have been found in putative botanical products, but their side effects are unpredictable in different people and in different doses [76].

\section{Hyphenated techniques}

Schramek et al. [77] screened multiple identical samples of herbal supplements for PDE-5is using LC-DAD and LC-MS. They found 14 compounds with the same pyrazolopyrimidine structure similar to sildenafil. Seven of these have already been previously published (piperazionafil, isopiperzionafil, oxoacetildenafil, (Z)-/ (E)-dicholorodenafil, gendenafil, and hydrohomoacetildenafil) [78]. The parent structure of sildenafil as well as its five analogues was also detected using LC-MS, UV, and NMR spectroscopic methods [79].

Liang et al. [2] proposed a method of LC/MS/MS because it is both rapid and reliable for the screening of complex matrices in a single run. Previously proposed methods such as HPLC, GC/MS, and LC/MS were said to be inadequate in their reliability for highthroughput screening because many herbal supplements contain a mixture of herbs and other products, and the complexity of the herbal supplements will interfere with spectroscopic and chromatographic assays. Liang et al. [2] used MRM to screen a mixture of compounds simultaneously by using three selected transitions for each compound to improve reliability on relative peak areas. Transitions are monitored under Optimal Collision Energy (OCE) and the analysis was sped up without compromising the mobile phases and also by having high selective MS/MS to ensure specificity [79]. When the LC/MS/MS method was tested, 74 of 200 samples tested positive for adulterants without false positives or false negatives.

Balayssac et al. [80] conducted a screening of nine sexual enhancement herbal dietary supplements that were intended to be marketed in Southern Europe. A combination of NMR and MS was used to detect PDE-5is. Five PDE-5is were detected as adulterants: thiosildenafil (THIO), sildenafil (SILD), tetrahydropalmatine (THP), phentolamine (PHE), and a newly detected adulterant, PP-THHS. IR spectroscopy as a supplement to NMR and MS was used for the determination of the identity of PP-THHS. Eight of the nine sexual enhancement herbal dietary supplements unequivocally were found to be adulterated with PDE-5is, four were found to contain PP-THHS, one thiosildenafil, two contained both sildenafil and tetrahydropalmatine, and one was found to contain phentolamine. 
Johansson et al. [81] created an analytical platform using LCQTOF-MS in combination with NMR spectroscopy to analyze unknown compounds in various types of herbal supplements. The World Health Organization (WHO) found that there were counterfeit products that had been falsely labeled and they either did not contain the APIs stated, or contained too little or too much, or had a different API all together [82]. These findings pose a serious health risk to consumers since some falsely identified supplements have caused deaths in the past. Martino et al. [83], in a review, discussed colorimetry, TLC, GC, HPLC, MS, and different vibrational spectroscopic methods.

A separate study also proved that ${ }^{1} \mathrm{H}$ NMR was a beneficial tool in identifying and quantifying adulterants [84]. A more difficult task, rather than just identification and quantification, is determining whether a substance is legitimate or counterfeit. One successful study that was able to achieve this using chemometrics and chromatographic fingerprinting methods based on HPLC-UV data to determine counterfeit erectile dysfunction drugs [85].

Liquid chromatography for the LC-QTOF-MS procedures was performed on a 1290 Infinity UHPLC equipped with a diode array detector. Quantification and identification for QTOF-MS used a database that was developed in-house. In the beginning, it should be stated that it contained around 4200 pharmaceutical compounds. For compounds that were almost identical to the parameters in the QTOF-MS database, more in-depth information was required. Other in-house databases were created for this purpose that contained information like MS/MS data, retention times on the chromatographic columns for specific substances, and investigations of UV spectra. Five standard NMR experiments were used: ${ }^{1} \mathrm{H},{ }^{13} \mathrm{C}$ attached proton test, 2-dimensional gradient $\mathrm{H}, \mathrm{H}-$ COSY, 2D gradient H,C-HSQC, and 2D gradient H,C-HMBC. The experiments were conducted over a five-year period with 150 to 250 samples analyzed each year. The most difficult part of this process was deciding how to start screening for APIs for various samples. A combination of LC-QTOF-MS and NMR was proven to be very effective when screening for adulterants in pharmaceutical tablets and capsules, herbal food supplements, ointments, and creams. The procedure was made easiest when LC-QTOF-MS only generated one peak, the MS spectrum generated only one hit in the database search, LC retention time with a reference compound and/or UV spectrum confirmed the hit, and identification was made with MS. NMR can readily confirm the identity and can be followed up with quantitative determination of the adulterant content in the product by qNMR $[86,87]$. However, this was not the case most of the time and other routes had to be taken in order to identify the adulterants. Thus, NMR can be applied directly when the adulterant in question needs to be found by using the spectra added to the NMR library created. This database has been divided into two different sub-databases: (1.) slimming products and (2.) products for pain. A screening procedure was performed on each of these product types and searched for adulterants within them.

1. In weight-loss products, a collaboration with Swedish Customs was made and 43 supplements were screened using LCQTOF-MS. Of them, 21 were adulterated with products such as sibutramine, orlistat, sildenafil, fluoxetine, and yohimbine.

2. When searching for products that treated pain, Fortodol was one of the first and was advertised as an herbal product. There were reports of liver damage due to this product that suspected the presence of NSAIDs. The API found in Fortodol was nimesulide, which is a COX-2 inhibitor and is not approved in many countries because of a hepatotoxicity risk.
The above method proves that LC-QTOF-MS and NMR used in conjunction can accurately identify and quantify adulterants present in all types of herbal supplements. This process has been applied to thousands of samples and can usually be performed without using reference samples, which makes it a more convenient method.

Deconinck et al. [88] have devised a way to use ATR-IR to detect sibutramine at inspection sites. ATR-IR is unique because unlike other more common methods, there is no sample preparation, which allows for the screening of samples both in the solid and liquid form. Using this method, Deconinck et al. [88] screened 125 dietary supplements that were suspected to contain sibutramine. After screening, they used chemometric methods to evaluate the data. Combinations of exploratory and modeling methods were used. It was found that principle component analysis (PCA) using the Yenyukov index for exploratory and k-Nearest Neighbors (k-NN) for modeling obtained the most accurate and reliable results. The k-NN showed a correct classification rate (CCR) of $83 \%$ and only three samples were misclassified when an external validation was done. All of the misclassified samples were found to be false positives. Their results concluded that ATR-IR and chemometrics were able to detect sibutramine in adulterated food supplements and powders. This technique was able to detect sibutramine in concentrations of $3 \mathrm{mg}$ to $30 \mathrm{mg}$ in powders ranging from $300 \mathrm{mg}$ to $20 \mathrm{~g}$. This technique is well adapted for inspections because there is no sample preparation and the instruments used are compact.

Lorcaserin is a drug that is used as an appetite suppressant for weight loss. The FDA approved it in 2012 [89]. Due to its side effects like euphoria and hallucinations at higher doses, lorcaserin is now listed as a Schedule IV controlled substance [90]. "Lose quickly" is a French dietary supplement that is available in capsule formulation. It was subjected to ultra-performance liquid chromatography (UPLC)-MS, IR, and NMR analyses. The NMR indicated the presence of suspected adulterants; therefore, flash chromatography was utilized to further study the sample. The UPLC, ${ }^{1} \mathrm{H}$ and ${ }^{13} \mathrm{C}$ NMR, and MS signals indicated a heterocyclic chemical compound made up of a benzene ring attached to an azapane ring that was unequivocally lorcaserin. The qNMR technique is used for quantifying components of complex mixtures. It is useful in this scenario because it does not require a reference standard. The calculated amount of lorcaserin in each capsule of "Lose quickly" was $6.6 \pm 0.8 \mathrm{mg}$ per day, while the recommended dosage of the drug Belviq (lorcaserin hydrochloride) is $10 \mathrm{mg}$ twice per day [91]. Belviq is used for serious weight management with a calorie-oriented diet. In spite of the small amount of lorcaserin present in "Lose quickly", the public was using without knowing that it contained a harmful chemical compound. Thus, an overdose of "Lose quickly" could lead to an unexpected overdose of lorcaserin.

Gold Nine Soft Capsules is a Chinese herbal medicine that is used to treat hypertension. Liquid chromatography-high-resolution mass spectrometry (LC-HRMS) was utilized for the identification of compounds in this HMP. The use of liquid chromatography, mass spectrometry, solid-phase extraction, and nuclear magnetic resonance (LC-MS-SPE/NMR) following LC-HRMS allowed for an analysis of isolated adulterants in this herbal product. LC-MSSPE/NMR is beneficial as it allows for the rapid identification of adulterants without the need for reference standards. Amlodipine (blocks calcium channels), indapamide (diuretic), and valsartan (angiotensin II receptor antagonist) were discovered as components of Gold Nine Soft Capsules [92]. It was determined 
that each casing of the Gold Nine Soft Capsules contained $1.52 \pm 0.10 \mathrm{mg}$ of amlodipine, $1.52 \pm 0.07 \mathrm{mg}$ of indapamide, and $40.46 \pm 2.44 \mathrm{mg}$ of valsartan. It is possible that the significant amount of valsartan could be due to the insolubility of the oily formulation and absorption on to the gelatin shell of the capsule. The Gold Nine Soft Capsules were tested in hypertensive rats. Additionally, a combination of amlodipine, indapamide, and valsartan was tested in an identical population. Both treatments showed the same result: brief increased heart rate. Each of the three drugs was tested individually for the lowering of blood pressure and to see specific adverse reactions. The doses of valsartan administered to the rats had the most significant effect on blood pressure. In conclusion, the three drugs in combination will produce a longer lasting rather than a stronger effect in hypertensive patients.

\section{Thin-layered-based analytical techniques}

In a study funded by the Chinese government, Zhu et al. [93] developed a rapid and reliable TLC-SERS technique for the determination of adulterants in herbal supplements. The preliminary experiment for this technique was carried out in 2013 and the technique enabled qualitative identification of adulterants in antidiabetic herbal supplements with few false-positive results. The TLC technique was chosen because of its already well-established history and the benefits of its simple operation, the low cost for drug quality verification, its high-throughput potential, and its ease of portability $[94,95]$. Although TLC has all of these benefits, this technique requires reference chemicals and a chromogenic agent. During the experiments conducted by Zhu et al. [93], four reference chemicals were chosen from the drug class's biguanide and thiazolidinedione. The reference chemicals were obtained from the National Institute for Food and Drug Control of China: phenformin hydrochloride (PHE), metformin hydrochloride (MET), ROS, and pioglitazone hydrochloride (PIO). Raman spectra were obtained using a portable Raman spectrometer (BWS415) at an excitation wavelength of $785 \mathrm{~nm}$. Two different types of TLC plates, silica gel $60-\mathrm{F}_{254}$ plates and high-performance silica gel $60-\mathrm{F}_{254}$ plates, were used. Spots were visualized by the use of an UV lamp (WFH-203B) at $254 \mathrm{~nm}$, and UV-visible (UV-VIS) absorption spectra of silver colloids were collected using a Varian Cary 100 Conc spectrometer. Microwave heating for the preparation of silver colloids was best suited for the experiment as it enhanced all four of the reference compounds when applied.

The simulated experiment proved that the TLC-SERS technique was able to detect trace amounts of adulterants even if the chromatographic spots of the analytes were not visible in UV light and/or the scattering coefficient was low. It was noted, however, that in order to obtain sufficient and definitive identification from Raman peaks, at least four or five peaks specific to each drug compound were needed. To further test this technique, Zhu et al. [93] applied it to 12 botanical products provided by the Shandong Institute for Food and Drug Control. The TLC-SERS technique determined that three samples were adulterated with ROS, while one sample was adulterated with both ROS and phenformin hydrochloride (PHE). These results were verified by liquid chromatography-triple quadrupole mass spectrometry (LC-MSMS).

Cai et al. [96] have developed a rapid screening technique using TLC and HPLC coupled with PDA-MS (HPLC-PDA-MS) for the simultaneous determination of eight PDE-5is. These eight PDE-5is included sildenafil, hongdenafil, homosildenafil, hydroxyhomosildenafil, vardenafil, pseudovardenafil, tadalafil, and aminotada- lafil. The TLC and HPLC-PDA-MS techniques were applied in this study to rapidly screen and determine the presence of PDE-5is in 36 commercial Chinese Herbal supplements. These techniques were proven successful, the TLC technique significantly reduced the analysis time, and the HPLC-PDA-MS technique had good sensitivity, precision, and accuracy.

The TLC technique can be used effectively for rapid screenings of PDE-5is in suspected adulterated HMPs. UV absorption spectra overlay can be used to identify the PDE-5is. The HPLC-PDA-MS and HPLC-UV techniques were both tested for the screening and identification of the eight PDE-5is used to adulterate HMPs. The identification of the adulterants in herbal supplements was determined by comparing retention times, UV spectra, and MS spectra of reference PDE-5is with those extracted from the herbal supplements. Ten of thirty-six herbal supplements marketed as aphrodisiacs were found to contain PDE-5is as adulterants.

Lv et al. [97] also developed a method similar to that developed by Zhu et al. [93] in which both used TLC-SERS to detect adulterants, but there were a few notable differences. Lv et al. developed their technique to the alkaloid ephedrine and its analogues used to adulterate weight-loss botanical products. EP, PSE, MEP, and NEP were the most popular adulterants used in weight-loss HMPs in their experiments, but they are also used clinically to treat respiratory ailments (i.e., asthma, colds, influenza, rhinitis). Although some of these drugs are used clinically, they have been known to have adverse side effects like cardiovascular problems, significant sympathomimetic activity, and central side effects. However, ephedrine products pose a greater risk to athletes because they act like an adrenaline boost and have the potential to hide the signs of fatigue. These products increase metabolism, increase blood pressure, and put added stress on the heart, which could allow athletes to push beyond their normal limits. This technique was developed for the direct identification of trace adulterants in HMPs without requiring reference substances. An analytical method was developed with eight common peaks shared by the four ephedrine analogues (EP, PSE, MEP, NEP) for a rapid and reliable detection. The four ephedrine analogues used as reference chemicals to develop the analytical method were purchased from the Chinese National Institutes for Food and Drug Control. In this experiment, only the high-performance glass silica gel, thin-layer chromatography scanner, and UV analyzer (WFH-203B) at $365 \mathrm{~nm}$ were used. The Raman spectra were recorded on a portable Raman spectrometer (BWS415) at $785 \mathrm{~nm}$ and an Agilent Technologies 1290 Infinity-6538 UHD AccurateMass UPLC-QTOF/MS verified the results. An important aspect that differed in this experiment was the use of DFT. DFT provides a relatively efficient and unbiased tool to compute the ground state energy in realistic models of bulk materials and their surfaces. The DFT was applied to Raman spectra obtained from EP, PSE, MEP, and NEP. The DFT found that the four analogues shared eight common peaks, which helped illuminate one of the four specific adulterants illegally added to HMPs when scanning on site with no reference materials available.

Results prove that the TLC-SERS technique proposed by Lv et al. [97] is able to quickly and reliably detect the four ephedrine analogues as adulterants in HMPs or botanical products in trace amounts with no reference materials available. This technique was applied to nine samples of weight-loss HMPs provided by the Shandong Institute for Food and Drug Control. The outcomes showed that two samples were adulterated, one with PSE and the other with NEP. The TLC-SERS technique results were confirmed by UPLC-QTOF/MS. 


\section{Conclusions}

$\nabla$

Some herbal medicinal products have been reported to cause severe adverse reactions due to their adulteration. PDE-5is, sibutramine, and fenfluramine are common examples of adulterants found in HMPs that have led people to be hospitalized. With LC-MS and combined methods, it is becoming easier to detect adulterants and confirm their presence. However, in order to use these techniques, products have to be brought to the laboratories for screening. Due to this inconvenience and the growth of the HMP market, the need for mobile screening techniques is becoming increasingly more apparent. Attenuated total reflectance-infrared spectrometry and thin-layer chromatography are becoming a necessity in the growing market due to their practicality and quick run time.

\section{Future Perspectives}

$\nabla$

Zhu et al. [93] have begun to create a finite database for these portable scanning techniques, but this database needs to be expanded. This database could potentially be an online resource categorizing drug classes by characteristics, intensities, and shifts of the analytical techniques. This would make adulteration more difficult for botanical product manufacturers while keeping the consumers safe. Another important future perspective is the ongoing expansion of the USP Food Fraud Database and the development of the USP Dietary Supplement Adulteration Database. These are repositories of international food and dietary supplement ingredients fraud reports and are associated with analytical techniques, which will facilitate fraud-food-ingredients-dietary supplements. The American Botanical Council and the Food Protection and Defense Institute sponsor the U.S. Pharmacopoeial Conference. This experience allows the attendees to learn about fraud and adulteration in food products and dietary supplements. The ABC-AHP-NCNPR Botanical Adulteration Program from the American Botanical Council continues to support educational activities to prevent the adulteration of HMPs.

The FDA has also made a requirement for the supplement marketers to report all adverse reactions. The American Herbal Products Association (AHPA) has made the push over the last several years and is still making the supplement industry more transparent to consumers.

Among the European Union initiatives to prevent adulteration of HMPs, Rapid Alert System for Food and Feed (RASFF) provides an efficient mechanism to identify adulterations so that different EU member states can take immediate actions on the corresponding products in the market.

\section{Acknowledgements \\ $\nabla$}

A.I.C. is indebted to the Harrison School of Pharmacy for the financial support through New Faculty Start Up, and Nature's Sunshine Inc. for supporting our research on the quality of botanical dietary supplements. M.P.G. acknowledges support from the SENACYT SNI program.

\section{Conflict of Interest \\ $\nabla$}

The authors do not have any conflict of interest.

\section{References}

1 Chan TY, Critchley JA. Usage and adverse effects of Chinese herbal medicines. Hum Exp Toxicol 1996; 15: 5-12

2 Liang $Q$ Luo G, Wang $Y$. Rapid and reliable determination of illegal adulterants in herbal medicines and dietary supplements by LC/MS/ MS. J Pharm Biomed Anal 2006; 40: 305-311

3 Yee SK, Chu SS, Xu YM, Choo PL. Regulatory control of Chinese Proprietary Medicines in Singapore. Health Policy 2005; 71: 139-144

4 Sahoo N, Manchikanti P, Dey S. Herbal drugs: standards and regulation. Fitoterapia 2010; 81: 462-471

5 Colson K, Luchsinger S, Hicks JM. Adulterated natural product extract detection - Viagra derivatives. Available at http://www.theresonance. com/adulterated-natural-products/. Accessed June 4, 2015

6 Teschke R, Wolff A, Frenzel C, Eickhoff A, Schulze J. Herbal traditional Chinese medicine and its evidence base in gastrointestinal disorders. World J Gastroenterol 2015; 21: 4466-4490

7 Ernst E. Toxic heavy metals and undeclared drugs in Asian herbal medicines. Trends Pharmacol Sci 2002; 23: 136-139

8 Ernst E. Adulteration of Chinese herbal medicines with synthetic drugs: a systematic review. J Intern Med 2002; 252: 107-113

9 Pradesh A. Adulteration of toddy continues unabated (The Hindu, August 29, 2009). Available at http://www.thehindu.com/todays-paper/ tp-national/tp-andhrapradesh/adulteration-of-toddy-continuesunabated/article215606.ece. Accessed November 17, 2015

10 American Botanical Council. About the ABC-AHP-NCNPR Botanical Adulterants Program. Available at http://cms.herbalgram.org/BAP/ BotanicalAdulterantsIndex.html\#AbouttheProgram. Accessed June 5, 2015

11 European Commission - Public Health. Medicinal products for human use. Available at http://ec.europa.eu/health/human-use/herbalmedicines/index_en.htm. Accessed November 17, 2015

12 Bronstein AC, Spyker DA, Cantilena jr. LR, Green J, Rumack BH, Heard SE. 2006 Annual Report of the American Association of Poison Control Centers' National Poison Data System (NPDS). Clin Toxicol (Phila) 2007; 45: 815-917

13 Gardiner P, Sarma DN, Low Dog T, Barrett ML, Chavez ML, Ko R, Mahady GB, Marles RJ, Pellicore LS, Giancaspro GI. The state of dietary supplement adverse event reporting in the United States. Pharmacoepidemiol Drug Saf 2008; 17: 962-970

14 United States Government Accountability Office. Dietary supplements: FDA may have opportunities to expand its use of reported health problems to oversee products (GAO Publication No. GAO-13-244; 2013). Available at http://www.gao.gov/products/GAO-13-244. Accessed June 5, 2015

15 Vohra S, Cvijovic K, Boon H, Foster BC, Jaeger W, LeGatt D, Cembrowski G, Murty M, Tsuyuki RT, Barnes J, Charrois TL, Arnason JT, Necyk C, Ware M, Rosychuk RJ. Study of natural health product adverse reactions (SONAR): active surveillance of adverse events following concurrent natural health product and prescription drug use in community pharmacies. PLoS One 2012; 7: e45196

16 Gupta MP. Herbal medicinal products. Pharmaceutical Policy and Law 2015; 17: 231-249

17 Nisoli E, Carruba MO. An assessment of the safety and efficacy of sibutramine, an anti-obesity drug with a novel mechanism of action. Obes Rev 2000; $1: 127-139$

18 Nakadai A, Inagaki H, Minami M, Takahashi H, Namme R, Ohsawa M, Ikegami S. Determination of the optical purity of N-nitrosofenfluramine found in the Chinese slimming diet. Yakugaku Zasshi 2003; 123: 805-809

19 Lai V, Smith A, Thorburn D, Raman VS. Severe hepatic injury and adulterated Chinese medicines. BMJ 2006; 332: 304-305

20 Lau G, Lo DS, Yao YJ, Leong HT, Chan CL, Chu SS. A fatal case of hepatic failure possibly induced by nitrosofenfluramine: a case report. Med Sci Law 2004; 44: 252-263

21 Binkley K, Knowles SR. Sibutramine and panic attacks. Am J Psychiatry 2002; 159: 1793-1794

22 Cordeiro $Q$ Vallada H. Sibutramine-induced mania episode in a bipolar patient. Int J Neuropsychopharmacol 2002; 5: 283-284

23 Taflinski T, Chojnacka J. Sibutramine-associated psychotic episode. Am J Psychiatry 2000; 157: 2057-2058

24 Vidal C, Quandte S. Identification of a sibutramine-metabolite in patient urine after intake of a "pure herbal" Chinese slimming product. Ther Drug Monit 2006; 28: 690-692 
25 Ministry of Health, Labour and Welfare (Japan). Unauthorised drugs. Available at http://www.mhlw.go.jp/english/. Accessed November 17, 2015

26 Yuen YP, Lai CK, Poon WT, Ng SW, Chan AYW, Mak TWL. Adulteration of over-the-counter slimming products with pharmaceutical analogues an emerging threat. Hong Kong Med J 2007; 216-220

27 Jung J, Hermanns-Clausen M, Weinmann W. Anorectic sibutramine detected in a Chinese herbal drug for weight loss. Forensic Sci Int 2006; 161: 221-222

28 European Medicines Agency. European Medicines Agency recommends suspension of marketing authorisations for sibutramine. [Press release EMA/39408/2010]. London: EMA; 2010

29 Food and Drug Administration. FDA drug safety communication: FDA recommends against the continued use of Meridia (sibutramine). Available at http://www.fda.gov/Drugs/DrugSafety/ucm228746.htm. Accessed October 8, 2015

30 Patel DN, Li L, Kee CL, Ge X, Low MY, Koh HL. Screening of synthetic PDE-5 inhibitors and their analogues as adulterants: analytical techniques and challenges. J Pharm Biomed Anal 2014; 87: 176-190

31 Venhuis BJ, de Kaste D. Towards a decade of detecting new analogues of sildenafil, tadalafil and vardenafil in food supplements: a history, analytical aspects and health risks. J Pharm Biomed Anal 2012; 69: 196208

32 Gilard V, Balayssac S, Tinaugus A, Martins N, Martino R, Malet-Martino $M$. Detection, identification and quantification by ${ }^{1} \mathrm{H}$ NMR of adulterants in 150 herbal dietary supplements marketed for improving sexual performance. J Pharm Biomed Anal 2015; 102: 476-493

33 Lam YH, Poon WT, Lai CK, Chan AY, Mak TW. Identification of a novel vardenafil analogue in herbal product. J Pharm Biomed Anal 2008; 46: 804-807

34 Cohen PA, Zeijlon R, Nardin R, Keizers PH, Venhuis B. Hemorrhagic stroke probably caused by exercise combined with a sports supplement containing $\beta$-methylphenylethylamine (BMPEA): a case report. Ann Intern Med 2015; 162: 879-880

35 Raterman K. BMPEA/Acacia rigidula Controversy Fuels Further Criticism of Botanicals. HerbalGram 2015; 12: 60

36 Palmer ME, Haller C, McKinney PE, Klein-Schwartz W, Tschirgi A, Smolinske SC, Woolf A, Sprague BM, Ko R, Everson G, Nelson LS, Dodd-Butera $T$, Bartlett WD, Landzberg BR. Adverse events associated with dietary supplements: an observational study. Lancet 2003; 361: 101-106

37 China Food and Drug Administration. Announcement of the China Food and Drug Administration about the illegal production and sale of Ginkgo leaf products by the Guilin Xingda Pharmaceutical Company Ltd. and other companies. Beijing, China; 19 May 2015. Available at www.sda.gov.cn/WS01/CL0087/119540.html. Accessed October 13, 2015

38 Mathon C, Ankli A, Reich E, Bieri S, Christen P. Screening and determination of sibutramine in adulterated herbal slimming supplements by HPTLC-UV densitometry. Food Addit Contam Part A Chem Anal Control Expo Risk Assess 2014; 31: 15-20

39 European Medicines Agency. Committee for medicinal products for human use. Referral Sibutramine. CHMP/4514/02. London: EMA; 2002

40 Poon WT, Ng SW, Lai CK, Chan YW, Mak WL. Factitious thyrotoxicosis and herbal dietary supplement for weight reduction. Clin Toxicol (Phila) 2008; 46: 290-292

41 Firstenberg J. FDA panel votes against new obesity drug Qnexa. Available at http://www.digitaljournal.com/article/294716. Accessed July 15,2015

42 Piggee C. Investigating a not-so-natural high. Anal Chem 2009; 81: 3205-3207

43 Auwärter V, Dresen S, Weinmann W, Müller M, Pütz M, Ferreirós N. 'Spice' and other herbal blends: harmless incense or cannabinoid designer drugs? J Mass Spectrom 2009; 44: 832-837

44 Uchiyama N, Kikura-Hanajiri R, Kawahara N, Haishima Y, Goda Y. Identification of a cannabinoid analog as a new type of designer drug in a herbal product. Chem Pharm Bull 2009; 57: 439-441

45 Auwärter V. Synthetic cannabinoids in herbal products. Available at https://www.unodc.org/documents/scientific/Synthetic_Cannabinoids.pdf. Accessed November 17, 2015

46 U.S. Food and Drug Administration. Tainted products marketed as dietary supplements_CDER. Available at http://www.accessdata.fda.gov/ scripts/sda/sdNavigation.cfm?sd=tainted_supplements_cder\&display All $=$ false\&page $=5$. Accessed November 17, 2015

47 American Botanical Council. Many "grapefruit seed extracts" adulterated, says nonprofit research consortium. Available at http://cms.
herbalgram.org/press/2012/Many_GFSE_Adulterated_Says_Nonprofit_ Research_Consortium.html?t=1338823765\&ts=1447688132\&signature= 8dff4ede0721f8f1c7bf82f7f11cf3d6. Accessed May 28, 2015

48 Geller A, Shehab N, Weidle N, Lovegrove M, Wolpert B, Timbo B, Mozersky $R$, Budnitz D. Emergency department visits for adverse events related to dietary supplements. N Engl J Med 2015; 373: 1531-1540

49 Vaclavik L, Krynitsky AJ, Rader JI. Mass spectrometric analysis of pharmaceutical adulterants in products labeled as botanical dietary supplements or herbal remedies: a review. Anal Bioanal Chem 2014; 406: 6767-6790

50 Metz TO, Zhang Q Page JS, Shen Y, Callister SJ, Jacobs JM, Smith RD. The future of liquid chromatography-mass spectrometry (LC-MS) in metabolic profiling and metabolomic studies for biomarker discovery. Biomark Med 2007; 1: 159-185

51 Thet $K$. Gas chromatography. Available at http://chemwiki. ucdavis.edu/Core/Analytical_Chemistry/Instrumental_Analysis/ Chromatography/Gas_Chromatography. Accessed November 17, 2015

52 Chatham JC, Blackband SJ. Nuclear magnetic resonance spectroscopy and imaging in animal research. ILAR J 2001; 42: 189-208. Available at http://ilarjournal.oxfordjournals.org/content/42/3/189.full.pdf.html. Accessed November 17, 2015

53 Advantages and disadvantages of capillary electrophoresis. Available at http://www.chromatographytoday.com/news/electrophoreticseparations/35/breaking_news/advantages_and_disadvantages_of capillary_electrophoresis/32342/. Accessed November 17, 2015

54 Wu X, Zhu B, Lu L, Huang W, Pang D. Optimization of a solid phase extraction and hydrophilic interaction liquid chromatography-tandem mass spectrometry method for the determination of metformin in dietary supplements and herbal medicines. Food Chem 2012; 133: 482488

55 Lacina O, Zachariasova M, Urbanova J, Vaclvikova M, Cajka T, Hajslova J. Critical assessment of extraction methods for the simultaneous determination of pesticide residues and mycotoxins in fruits, cereals, spices and oil seeds employing ultra-high performance liquid chromatography-tandem mass spectrometry. J Chromatogr A 2012; 1262: 8-18

56 Becue I, Van Poucke C, Van Peteghem C. An LC-MS screening method with library identification for the detection of steroids in dietary supplements. J Mass Spectrom 2011; 46: 327-335

57 Li N, Cui M, Lu X, Qin F, Jiang K, Li F. A rapid and reliable UPLC-MS/MS method for the identification and quantification of fourteen synthetic anti-diabetic drugs in adulterated Chinese proprietary medicines and dietary supplements. Biomed Chromatogr 2010; 24: 1255-1261

58 Kesting JR, Huang J, Sorensen D. Identification of adulterants in Chinese herbal medicine by LC-HRMS and LC-MS-SPE/NMR and comparative in vivo study with standards in a hypertensive rat model. J Pharm Biomed Anal 2010; 51: 705-711

59 Woo H, Kim JW, Han KM, Lee JH, Hwang IS, Lee JH, Kim J, Kweon SJ, Cho S, Chae KR, Han SY, Kim J. Simultaneous analysis of 17 diuretics in dietary supplements by HPLC and LC-MS/MS. Food Addit Contam Part A Chem Anal Control Expo Risk Assess 2013; 30: 209-217

60 Bogusz MJ, Hassan H, Al-Enazi E, Ibrahim Z, Al-Tufail M. Application of LC-ESI-MS-MS for detection of synthetic adulterants in herbal remedies. J Pharm Biomed Anal 2006; 41: 554-564

61 Van Poucke C, Detavernier C, Van Cauwenberghe R, Van Peteghem C. Determination of anabolic steroids in dietary supplements by liquid chromatography-tandem mass spectrometry. Anal Chim Acta 2007; 586: $35-42$

62 Aqai P, Belsa NG, Major H, Pedotti M, Varani L, Verrerro VEV, Haasnoot W, Nielin MWF. Receptor-based high-throughput screening and identification of estrogens in dietary supplements using bioaffinity liquidchromatography ion mobility mass spectrometry. Anal Bioanal Chem 2013; 405: 9427-9436

63 Aqai P, Cevik E, Gerssen A, Haasnoot W, Nielen MWF. High-throughput bioaffinity mass spectrometry for screening and identification of designer anabolic steroids in dietary supplements. Anal Chem 2013; 85: 3255-3262

64 Au AM, Ko R, Boo FO, Hsu R, Perez G, Yang Z. Screening method for drugs and heavy metals in Chinese patent medicines. Bull Environ Contam Toxicol 2000; 65: 112-119

65 Song F, El-Demerdash A, Lee SJSH. Screening for multiple phosphodiesterase type 5 inhibitor drugs in dietary supplement materials by flow injection mass spectrometry and their quantification by liquid chromatography tandem mass spectrometry. J Pharm Biomed Anal 2012; 70: $40-46$ 
66 Song F, Monroe D, El-Demerdash A, Palmer C. Screening for multiple weight loss and related drugs in dietary supplement materials by flow injection tandem mass spectrometry and their confirmation by liquid chromatography tandem mass spectrometry. J Pharm Biomed Anal 2014; 88: 136-143

67 Zhou Z, Zhang J, Zhang W, Bai Y, Liu H. Rapid screening for synthetic antidiabetic drug adulteration in herbal dietary supplements using direct analysis in real time mass spectrometry. Analyst 2011; 36: 2613-2618

68 Wang $H$, Wu Y, Sun W, Ding L, Guo B, Chen B. Rapid screening for illicit additives in weight loss dietary supplements with desorption corona bean ionization (DCBI) mass spectrometry. Food Addit Contam Part A Chem Anal Control Expo Risk Assess 2012; 29: 1194-1201

69 Cheng HL, Tseng MC, Tsai PL, Her GR. Analysis of synthetic chemical drugs in adulterated Chinese medicines by capillary electrophoresis/ electrospray ionization mass spectrometry. Rapid Commun Mass Spectrom 2001; 15: 1473-1480

70 Auricchio MT, Batistic MA, Markman BEO. Deteaccao de anorexigenos e benzodiazepinicos em formulacoes 'naturais' empregadas em regimes de emageccimento. Rev Inst Adolfo Lutz 1991; 51: 105-110

71 Almeida AE, Ribeiro ML, Polese L. Determination of amfepremone hydrochloride, fenproporex, and diazepam in so-called 'natural' capsules used in the treatment of obesity. J Liq Chromatogr Relat Technol 2000; 23: $1109-1118$

72 de Carvalho LM, Correia D, Garcia SC, de Bairros AV, do Nascimento PC, Bohrer D. A new method for the simultaneous determination of 1,4 benzidiazepines and amfepramone as adulterants in phytotherapeutic formulations by voltammetry. Forensic Sci Int 2010; 202: 75-81

73 Cohen PA. Imported fenproporex-based diet pills from Brazil: a report of two cases. J Gen Intern Med 2009; 24: 430-433

74 Cohen PA. American roulette - contaminated dietary supplements. N Engl J Med 2009; 361: 1523-1525

75 de Carvalho LM, Martini M, Moreira AP, Garcia SC, Nascimento PC, Bohrer $D$. Determination of synthetic pharmaceuticals in phytotherapeutics by capillary zone electrophoresis with contactless conductivity detection (CE-C4D). Microchem J 2010; 96: 114-119

76 Sombra LL, Gomez MR, Olsina R, Martinez LD, Silva MF. Comparative study between capillary electrophoresis and high performance liquid chromatography in 'guarana' based phytopharmaceuticals. J Pharm Biomed Anal 2005; 5: 989-994

77 Schramek N, Wollein U, Eisenreich W. Pyrazolopyrimidines in 'all-natural' products for erectile dysfunction treatment: the unreliable quality of dietary supplements. Food Addit Contam Part A Chem Anal Control Expo Risk Assess 2015; 32: 127-140

78 Lin MC, Liu YC, Lin YL, Lin JH. Isolation and identification of a novel sildenafil analogue adulterated in dietary supplements. J Food Drug Anal 2008; $16: 15-20$

79 Wollein U, Eisenreich W, Schramek N. Identification of novel sildenafilanalogues in an adulterated herbal food supplement. J Pharm Biomed Anal 2011; 56: 705-712

80 Balayssac S, Gilard V, Zedde C, Martino R, Malet-Martino M. Analysis of herbal dietary supplements for sexual performance enhancement: first characterization of propoxyphenyl-thiohydroxyhomosildenafil and identification of sildenafil, thiosildenafil, phentolamine and tetrahydropalmatine as adulterants. J Pharm Biomed Anal 2012; 63: 135150
81 Johansson M, Fransson D, Rundlöf T, Huynh NH, Arvidsson T. A general analytical platform and strategy in search for illegal drugs. J Pharm Biomed Anal 2014; 100: 215-229

82 Substandard, spurious, falsely labelled, falsified and counterfeit (SSFFC) medical products. Available at http://www.who.int/mediacentre/factsheets/fs275/en/. Accessed November 17, 2015

83 Martino R, Malet-Martino M, Gilard V, Balayssac S. Counterfeit drugs: analytical techniques for their identification. Anal Bioanal Chem 2010; 398: 77-92

84 Holzgrabe $U$, Malet-Martino $M$. Analytical challenges in drug counterfeiting and falsification - the NMR approach. J Pharm Biomed Anal 2011; 55: 679-687

85 Deconinck E, Sacré PY, Courselle P, De Beer JO. Chemometrics and chromatographic fingerprints to discriminate and classify counterfeit medicines containing PDE-5 inhibitors. Talanta 2012; 100: 123-133

86 Rundlöf T, Mathiasson M, Bekiroglu S, Hakkarainen B, Bowden T, Arvidsson $T$. Survey and qualification of internal standards for quantification by ${ }^{1} \mathrm{H}$ NMR spectroscopy. J Pharm Biomed Anal 2010; 52: 645-651

87 Rundlöf T, McEwen I, Johansson M, Arvidsson T. Use and qualification of primary and secondary standards employed in quantitative ${ }^{1} \mathrm{H}$ NMR spectroscopy of pharmaceuticals. J Pharm Biomed Anal 2014; 93: $111-117$

88 Deconinck E, Cauwenbergh T, Bothy JL, Custers D, Courselle P, De Beer JO. Detection of sibutramine in adulterated dietary supplements using attenuated total reflectance-infrared spectroscopy. J Pharm Biomed Anal 2014; 100: 279-283

89 Fleming $W$, McClendon KS, Riche DM. New obesity agents: lorcaserin and phentermine/topiramate. Ann Pharmacother 2013; 47: 10071016

90 Shram MJ, Schoedel KA, Bartlett C, Shazer RL, Anderson CM, Sellers EM. Evaluation of the abuse potential of lorcaserin, a serotonin $2 \mathrm{C}$ (5HT2C) receptor agonist, in recreational polydrug users. Clin Pharmacol Ther 2011; 89: 683-692

91 Cunha J. Belviq side effects center - RxList. Available at http://www. rxlist.com/belviq-side-effects-drug-center.htm. Accessed November 17,2015

92 Williams AL. Drug Facts and Comparisons, 60th edition. St. Louis, MO: Wolters Kluwer Health; 2012

93 Zhu Q Cao Y, Cao Y, Chai Y, Lu F. Rapid on-site TLC-SERS detection of four antidiabetes drugs used as adulterants in botanical dietary supplements. Anal Bioanal Chem 2014; 406: 1877-1884

94 Lindahl I, Masson P. Improved sample and reagent pipetting with the MINILAB. J Clin Chem Clin Biochem 1990; 28: 949-950

95 Risha PG, Msuya Z, Clark M, Johnson K, Ndomondo-Sigonda M, Layloff T. The use of Minilabs to improve the testing capacity of regulatory authorities in resource limited settings: Tanzanian experience. Health Policy 2008; 87: 217-222

96 Cai Y, Cai TG, Shi Y, Cheng XL, Ma LY, Ma SC, Lin RC, Feng W. Simultaneous determination of eight PDE5-is potentially adulterated in herbal dietary supplements with TLC and HPLC-PDA-MS methods. J Liq Chromatogr Relat Technol 2010; 33: 1287-1306

97 Lv D, Cao Y, Lou Z, Li S, Chen X, Chai Y, Lu F. Rapid on-site detection of ephedrine and its analogues used as adulterants in slimming dietary supplements by TLC-SERS. Anal Bioanal Chem 2015; 407: 1313-1325 